\title{
Myths about fingerprint evidence: Basic facts countering miscarriage of justice. Part 1
}

\author{
SALEH MANSOUR \\ ORCID: 0000-0002-4111-4704 \\ Faculty of Criminology, Lebanese University \\ Beirut, Lebanon \\ SHITAL ZADE \\ ORCID: 0000-0003-1976-8477 \\ International Forensic Science Pvt. Ltd \\ Pune, Maharashtra, India \\ SHIPRA ROHATGI \\ ORCID: 0000-0003-0532-9908 \\ Amity Institute of Forensic Sciences, Amity University \\ Noida, India

\section{Slobodan OKLEVSKI} \\ ORCID: 0000-0002-1116-5631 \\ Ministry of Interior, Republic of North Macedonia
}

\begin{abstract}
The long practice of fingerprint science is accompanied by confusing thoughts affecting the interpretation of the fingerprint evidence recovered from a crime scene, and, consequently, prosecutors and judges' decisions as well. However, despite the tremen-


dous scientific and technological developments relating to fingerprint enhancement, processing, and usage, which clarify precise facts regarding the influence of deposition circumstances, substrate, light, air, temperature, and time factors on fingerprint secretions, misconceptions about fingerprints are still widespread within the law enforcement and judicial system. This problem prevents the proper usage of fingerprints in fighting crimes and supporting the justice system by strong physical evidence. This study aims to highlight some scientific facts about fingerprints as well as a new approach and reconceptualization of fingermarks as a tool for crime scene investigation and training. The article discusses twenty-four myths about fingerprints - part 1 covers ten of them and part 2 discusses the other fourteen.

Keywords: fingerprint aging, constituents, skin anatomy, processing techniques, delicate surfaces, fingerprint sensitivity, evidence interpretation, ACE-V methodology, AFIS

\section{Introduction}

A fingerprint or friction ridge is the skin located on the fingers, palms, and soles of human beings as well as animals such as chimpanzees and koalas. ${ }^{1}$ Most individuals are known to have unique, persistent, and permanent fingerprints, ${ }^{2}$ with an exception of people born with rare genetic conditions. ${ }^{3}$ When an item is touched, intentionally or unintentionally, there is always a transfer of material between it and the skin. Thus, the word "fingerprint" refers to the shapes of papillary ridges left on bearer surfaces when they are touched.

The fingermark is the trace left by a fingerprint and recovered at crime scenes. It has three main types regarding its visibility: latent, patent, and plastic/molded. Latent fingermarks are the most common - they require development and enhancement of some sort to be visualized. Patent fingermarks are visible and include fingermarks in blood, ink, or other colorants, and plastic prints are impressions left in soft material substrates such as wax, paint, putty, or any other substance that will soft-

${ }^{1}$ W.D. Hopkins et al, "Grip preference, dermatoglyphics, and hand use in captive chimpanzees (Pan troglodytes)", American Journal of Physical Anthropology 128, 2005, no. 1, pp. 57-62, https://doi.org/10.1002/ajpa.20093.

2 H.M. Daluz, Fingerprint analysis laboratory workbook, Boca Raton, FL 2018.

${ }^{3}$ R. Kaufman, "Mutated DNA causes no-fingerprint disease", National Geographic, 10.08.2011, https://www.nationalgeographic.com/news/2011/8/110809-fingerprints-skindisease-health-science-weird/ (accessed: 17.08.2020). 
en when handled. Fingermark enhancement can at times be complex and require sequential processing utilizing various spectroscopic, physical, chemical, physiochemical, and/or multi-nature techniques. It is important to realize that the most recognized and widely known process is dusting by fingerprint powder, which, despite its prevalence, is not the ideal process to develop fingermarks from all the substrates and in all cases.

This point is often overlooked, which poses a serious problem when many people concerned, such as law enforcement officers, investigators, prosecutors, and judges, are convinced that if the latent print could not be revealed by powder dusting of a certain substrate or delicate surface at the crime scene, that means the fingermarks have been disappeared, demolished, or destroyed. Consequently, they base their decisions on this myth. The fundamental role of fingerprints is to reveal crimes and deliver a solid proof of individual identification to the court.

What are the myths about fingerprint evidence? What is their weight in the scientific balance? This study is going to answer these two main questions.

\section{The fingerprint evidence is unreliable}

The fingerprint evidence, similarly to other disciplines of forensic science, faced plenty of criticism by scientific and legal analysts regarding the reliability of investigation and examination methods which rely on personal subjective conclusions. ${ }^{4}$ The main criticism of the National Research Council (NRC) of the National Academies of Science (NAS) and the President's Council of Advisors on Science and Technology (PCAST) was the lack of scientific and empirical basis to authenticate conclusions, which restricts their reasonable demonstration to the judiciary. ${ }^{5}$ Moreover, the mistaken practice of fingerprint individualization supports this kind of criticisms.

4 S.L. Cooper, "Challenges to fingerprint identification evidence: Why the courts need a new approach to finality", Mitchell Hamline Law Review 42, 2016, no. 2, http:// open.mitchellhamline.edu/mhlr/vol42/iss2/8 (accessed: 20.06.2020).

5 H.J. Swofford et al., "A method for the statistical interpretation of friction ridge skin impression evidence: Method development and validation”, Forensic Science International 287, 2018, pp. 113-26, https://doi.org/10.1016/j.forsciint.2018.03.043. 
One of the most famous cases is that of Brandon Mayfield, an American lawyer. Fingerprint traces were developed from a blue plastic bag containing detonators found at a railway station near the bombing terrorist crime scene in Madrid (Spain) on 11 March 2004, where several bombs exploded in a railway station, killing 191 people and wounding 2050. After identification, a digital copy of the traces was sent to the FBI in the United States, who identified Mayfield as the source of one of them, with 15 matching characteristics, which led to his arrest in May 2004 as a material witness in the case. Moreover, the FBI brought an independent fingerprint expert who stated that the quality of the prints' copy delivered from the Spanish police was poor and the image possibly included an overlay of another print, and highlighted the importance of examining the original image. ${ }^{6}$ The Spanish authorities disputed the FBI's conclusions and confirmed that the fingerprint traces had a positive match in their database, matching the thumb and middle of another individual called Ouhnane Daoud. This led to Mayfield's release after a two-week detention in a Multnomah County jail in Oregon. ${ }^{7}$

A comprehensive investigation of Mayfield's case held by the US Inspector General's Office, who in 2006 released a 273-page report, concluded that there is "unusual similarity" of the two fingerprints, and bias from the known prints of Mayfield led to the confusion of the three FBI examiners and the court-appointed expert. However, it also admitted the examiners' failure to adhere to the bureau's rules for identifying latent fingerprints, highlighted the FBI's overconfidence in its skills and the superiority of its examiners as well as in the power of IAFIS, and the pressure of working on a high-profile case as contributing to the error. As for the case's conclusion, the mistaken individualization was related to a substandard image, erroneous adhering to the standard operating procedures and human error, but not to the fingerprint science. ${ }^{8}$

6 OpenLearn, The Open University, https://www.open.edu/openlearn/health-sportspsychology/health/forensic-science-and-fingerprints/content-section-0 active-tab= description-tab (accessed: 14.06.2020).

7 S. Kershaw, E. Lichtblau, Kershaw S., Lichtblau E., "Questions about evidence in U.S. arrest in bombing", The New York Times, 22.05.2004, https:/www.nytimes.com/2004/ 05/22/us/questions-about-evidence-in-us-arrest-in-bombing.html (accessed: 14.06.2020).

8 U.S. Department of Justice, A review of the FBI's handling of the Brandon Mayfield case, March 2006. 

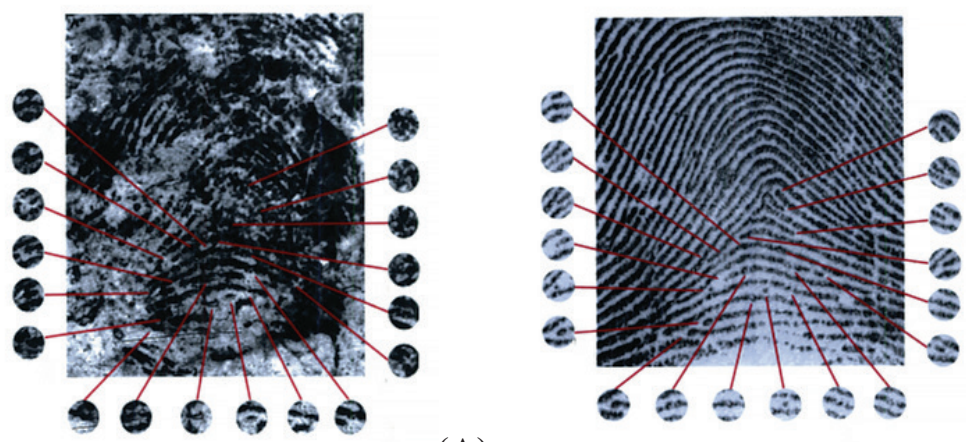

(A)

(B)

Figure 1. (A) Image of the fingermark developed from the plastic bag that was found near the scene of the March 2004 Madrid bombings. (B) Brandon Mayfield's fingerprint ${ }^{9}$

Two main methods were used to demonstrate the rareness of the fingerprint friction ridge characteristics.

1. Feature-based models, which involve calculating the probability estimates of the random correspondence minutiae distribution and configuration. Zhu et al. developed a family of mixture models to simulate the clustering property and tendency of minutiae features in fingerprint images, whereas the probability of random correspondence (PRC) was computed by a mathematical model, without investigating other mixture distribution on the minutiae locations and directions. ${ }^{10} \mathrm{Su}$ and Srihari developed a model to calculate the PRC, grounded on the spatial minutiae distribution, and the dependency of each one on nearby minutiae and the sureness of their occurrence in the evidence. ${ }^{11}$

2. Similarity matric models, which calculate the probability estimates from likelihood ratios determination for fingermark evidence evaluation based on the Automated Fingerprint Identification System (AFIS) distribution of similarity scores. ${ }^{12}$

9 Ibid.

10 Y. Zhu et al., "Statistical models for assessing the individuality of fingerprints", IEEE Transactions on Information Forensics and Security 2, 2007, no. 3.

11 C. Su, S. Srihari, "Evaluation of rarity of fingerprints in forensics", Proceedings of Neural Information Processing Systems, 6-9 December 2010, Vancouver, Canada, https://cedar.buffalo.edu/ srihari/papers/nips2010.pdf.

12 I. Alberink, A. de Jongh, C. Rodriguez, "Fingermark evidence evaluation based on automated fingerprint identification system matching scores: The effect of different 


\section{The fingerprint is composed of sweat and water which disappear rapidly by evaporation}

Eccrine sweat glands constitute a single type of fingerprint component sources, such as water, which is one of many sweat secretions. ${ }^{13} \mathrm{Al}-$ though these components differ in quality and quantity from the general chemical composition of sweat, their mixture is individual to each case and more complex to be identified.

In the first place, fingerprint constituents are composed of endogenous and exogenous sources. ${ }^{14}$ There are three main sources of endogeous components: eccrine glands, sebaceous glands, and apocrine glands.

The eccrine glands are also known as merocrine glands ${ }^{15}$ and their number is the highest in hands as well as soles of the feet. Their secretions are divided into inorganic and organic constituents. ${ }^{16}$ Examples of the first type: ammonia, bromide, chloride, fluoride, cobalt, copper, phosphate, sulphide, and water, whereas examples of the second type: amino acids, creatinine, enzymes, glucose, glycogen, lactic acid, lactate peptides, phenols, proteins, pyruvic acid, pyruvate, urea, uric acid, and vitamins. Almost all mentioned materials are not sensitive to environmental factors, such as temperature, sunlight, humidity, airflow, etc., neither are they subject to the evaporation process, although the majority of them are water-soluble materials. ${ }^{17}$

types of conditioning on likelihood ratios", Journal of Forensic Sciences 59, 2014, no. 1, pp. 70-81, https://doi.org/10.1111/1556-4029.12105; H.J. Swofford et al., op. cit.

13 M.V. Buchanan, K. Asano, A. Bohanon, Chemical characterization of fingerprints from adults and children, Washington, D.C. 1996; R.S. Croxton et al., "Variation in amino acid and lipid composition of latent fingerprints", Forensic Science International 199, 2010, pp. 93-102; Victoria Forensic Science Center Fingerprint Branch, Latent fingerprint composition, FPB training unit module 9, 2011.

14 A. Girod, R. Ramotowski, C. Weyermann, "Composition of fingermark residue: A qualitative and quantitative review", Forensic Science International 223, 2012, no. 1-3, pp. 10-24, https://doi.org/10.1016/j.forsciint.2012.05.018.

15 "Merocrine gland", Biology Online, https://www.biologyonline.com/dictionary/ merocrine-gland (accessed: 18.06.2020).

${ }^{16}$ G. de Paoli et al., "Photo- and thermal-degradation studies of select eccrine fingerprint constituents", Journal of the Forensic Science Society 55, 2010, no. 4, pp. 962 969, https://doi.org/10.1111/j.1556-4029.2010. 01420.x.

17 The Home Office Centre for Applied Science and Technology (CAST), Fingermark visualisation manual, 2014, http://www.officialpublicationsonline.co.uk.libproxy.

Nowa Kodyfikacja Prawa Karnego 59, 2021

(C) for this edition by CNS 
In the same fashion, eccrine glands play a critical role in forensic science since they cannot be controlled intentionally by the perpetrator - they are innervated by the autonomic nervous system, along with smooth muscles of all visceral structures and coordinating bodily responses, without requiring conscious or voluntary control. ${ }^{18}$ This gives an advantage to the criminal investigation: thermal and emotional provocations experienced throughout committing the crime activate the automatic response of sweat glands, granted that sweat constituents secreted through pores situated along the papillary ridges of the fingerprints, overlaying them, and deposited on the touched surfaces. ${ }^{19}$

This may be a comprehensive explanation for why the clarity of the perpetrators' fingermark impressions on a paper substrate is greater than fingermarks of other people who touched the same document. For instance, when attempting to cash out a fraudulent check from a bank, the perpetrator tries to control all indicators of their tension to avoid suspicion by bank employees. This leads to internal tension and acceleration in heartbeat and breathing, and an increase in secretions of amino acids and other constituents that will be transferred to the check through direct contact.

Sebaceous glands' secretions are only of the organic type; examples include: alcohols, fatty acids, fatty acid alkyl esters, glycerides, hydrocarbons, squalene, squalene degradation products (e.g. squalene epoxides, squalene hydroperoxides), sterols, sterol esters, wax esters. Although sebaceous glands are not found in the skin of palms and soles, ${ }^{20}$ they occur everywhere hair follicles are present, mainly on the skin of the forehead, face, and neck. ${ }^{21}$ Their secretions are transferred to the friction ridge areas by contamination when the hands touch the forehead, nose, chin, and scalp areas of the face, which is a typical human behavior, ${ }^{22}$

abertay.ac.uk/publications/download/9781782462347; H. Murota et al., "Sweat in the pathogenesis of atopic dermatitis", Allergology International 67, 2018, no. 4, pp. 455-459.

18 M. Richter, R. Wright, "Autonomic nervous system", [in:] Encyclopedia of behavioral medicine, New York 2012, https://www.researchgate.net/publication/28 0650893_Autonomic_nervous_system.

19 The Home Office Centre for Applied Science and Technology (CAST), op. cit.

20 A.V. Maceo, "Anatomy and physiology of adult friction ridge skin", [in:] National Institute of Justice, The fingerprint sourcebook, pp. 2-1-2-26.

21 The Home Office Centre for Applied Science and Technology (CAST), op. cit.

22 S. Dimond, R. Harries, "Face touching in monkeys, apes, and man: evolutionary origins and cerebral asymmetry", Neuropsychologia 22, 1984, pp. 227-233.

Nowa Kodyfikacja Prawa Karnego 59, 2021

(C) for this edition by CNS 
regardless of whether it happens intentionally or not. Despite the majority of sebaceous secretions constituents being water-insoluble, ${ }^{23}$ they are less sensitive to environmental circumstances.

Moreover, many scientific experimental studies found that both in fingermarks exposed to light and those stored in the dark, saturated fatty acids increased for 20 days, followed by a decrease below the initial amounts. $^{24}$ These observations can be interpreted as bacterial activities causing the increase in fatty acids as well as the subsequent decrease when triglycerides are completely broken down. By the same token, saturated acids with low molecular weights were also shown to increase over time by the effect of the oxidation products of squalene and some fatty acids such as nonanoic, hexadioic, and penta dioic acids. Since sebaceous secretions are not liquid, as a consequence they are not subject to evaporation. ${ }^{25}$

However, the exogenous constituents within the components of the fingerprint secretions that are foreign to the secretions of the different glands, are found on the friction ridge skin as a result of external contamination, and also might be found on the surface of the substrate before holding it. Among the most prominent pollutants that are found on the hands are the effects of foodstuffs, alcohol, cleaning materials, dirt, different oils, grease, charcoal, ink, chemicals such as soaps, skin moisturizers, and cosmetic products, traces of various narcotics, explosive substances, or body fluids such as blood. No matter how small the amounts of these substances are, they can help in developing the appearance of fingerprint impressions, either directly or through their interaction with the chemicals used in the development process. ${ }^{26}$

Furthermore, scientific research highlighted the inter-variation of the chemical composition of fingerprint secretions between one individual and another, as well as the occasional intra-variation of these

23 The Home Office Centre for Applied Science and Technology (CAST), op. cit.

24 De Paoli G. et al., op. cit.; N.E. Archer et al., "Changes in the lipid composition of latent fingerprint residue with time after deposition on a surface", Forensic Science International 154, 2005, no. 2-3, pp. 224-39, https://doi.org/10.1016/j.forsciint.20 04.09.120.

25 A. Girod, R. Ramotowski, C. Weyermann, op. cit.

26 The Home Office Centre for Applied Science and Technology (CAST), op. cit. 
secretions within the same individual. These variations are due to several factors, including metabolites of the type of food and drink or medicines and drugs consumed, as well as diseases, ${ }^{27}$ exercise, emotional and psychological conditions. It should be noted that the majority of the components from sweat glands are soluble in water, unlike the fatty components resulting from the secretions of the sebaceous and apocrine glands. ${ }^{28}$

The numerous factors that influence the fingermark constituents, which form a complex system, include the donor features, the deposition circumstances, the substrate nature, the environmental conditions, and the applied experimental techniques. ${ }^{29}$

Scientists have found about 346 materials in the mixture of the fingermark components. ${ }^{30}$ This means that the evaporation process will not be able to make all these components disappear, as mentioned above. When the deposited fingermark is fresh, dusting by powder is a perfect way for its development because the powder will adhere to the "wet" secretions, and the latent fingermark will be clear and visible. However, when the deposited fingermark is not fresh and the "wet" secretions have already evaporated due to time and environmental factors, then dusting by powder will not be the perfect way for the development process. This does not mean that the fingerprint has already disappeared or been demolished, but rather the chosen processing technique has to be different from dusting by powder.

In such a case, the individual variable conditions of the surface, the expected time of deposition, and environmental factors have to be taken into consideration to design the appropriate procedures and processing techniques. The main factors of the study are: the type of latent fingermark residue (visible, latent, patent), the type of substrate (porous, semi-porous, non-porous), the texture of the substrate (soft, thick,), its condition (clean, dirty, tacky, sticky, greasy, etc.), environmental conditions during and following the deposition (light, humidity, airflow, temper-

27 S. Francese et al., "Beyond the ridge pattern: multi-informative analysis of latent fingermarks by MALDI mass spectrometry", The Analyst 138, 2013, no. 15, pp. 4215-4228.

28 The Home Office Centre for Applied Science and Technology (CAST), op. cit.

29 A. Girod, R. Ramotowski, C. Weyermann, op. cit.

30 "Morphogenèse et composition des empreintes digitales", Police Scientifique, https://www.police-scientifique.com/empreintes-digitales/composition. 
ature, etc.), the time passed since the evidence was touched, the effects of destructive processing methods, and subsequent forensic examinations. ${ }^{31}$ Consequently, the proper chemical, physical, physicochemical, and/or spectroscopic techniques have to be applied in an appropriate order to get the best possible results of fingermark visibility and clarity - otherwise the risk of ruining the fragile latent is significant. ${ }^{32}$

\section{The fingerprint age does not exceed forty-eight hours}

This old myth was spread globally. ${ }^{33}$ Scientific research about fingerprint evidence constituents and behavior over time plays an important role in partially dispelling such an erroneous myth, even though it is still present and has a continuous negative influence on both criminal investigations and the judicial system.

Although the evaporation process of the fingerprint components has a great influence on water and water-soluble substances, it does not affect other components such as sebum, squalene, sulfate, magnesium, cholesterol, triglyceride, oleic acid, etc. in any way. In this context, Girod et al. examined the initial residues of fingerprint impressions and monitored the changes that occur over time within a period that extends up to $1,3,7$, 9, 20, 34 days, by using Fourier Transform Infrared Microscopy Technology (m-FTIR). Where the result of examining the initial impressions are prepared with diluted total reflection and single-point reflection patterns (ATR), and Single-Point Reflection Modes, it is possible to find the residue of the sweat and sebaceous gland secretions in recent impressions on substrates stored in a dark place. ${ }^{34}$

31 B. Yamashita, M. French, "Latent print development", [in:] National Institute of Justice, The fingerprint sourcebook, pp. 7-1-7-67, https:/www.ojp.gov/pdffiles1/nij/ 225320.pdf.

32 M. Fulton, "Latent chemistry: Development of fingerprints", Fulton Forensics, 27.11.2017, https:/www.linkedin.com/pulse/latent-chemistry-development-fingerprintsmike-fulton/ (accessed: 29.08.2020).

33 K. Wertheim, "Fingerprint age determination: Is there any hope?", Journal of Forensic Identification 53, 2003, no. 1, pp. 42-49.

34 A. Girod et al, "Fingermark initial composition and aging using Fourier transform infrared microscopy ( $\mu$-FTIR)", Forensic Science International 254, 2015, pp. 190, 194, https://doi.org/10.1016/j.forsciint.2015.07.022. 
In this framework, the analysis of chemical measurements showed that it is possible to classify the effects of fingerprints into groups based on the age criterion, regardless of the carrier surface, if they are stored in a box placed in a laboratory and exposed to a temperature of 20 degrees Celsius near the window. When fingermarks are preserved in darkness, it is possible to classify impressions of fingerprints on the same substrate in groups according to the age criterion, and thus the effect of the surface on examining the age of fingerprint printing if stored in the dark. ${ }^{35}$

Equally important are the results of using Partial Least Squares Regression (PLSR) which showed that it is possible to determine the age of a fingermark by a difference of three days concerning impressions passed from twenty to thirty-four days prior, and by a difference of one day concerning the most recent impressions, that is, one passed a day, three, seven, nine days beforehand, regardless of the type of substrate and the level of illumination. These are important results about determining the age of fingermarks - they reinforce the need to conduct additional research to demonstrate this model scientifically, verify its reliability and the extent of its limitations. ${ }^{36}$

Besides, a study on fingerprint aging published by German scientists shows that the scientific analysis of oleic acid by the mass spectral gas chromatography-MS/GC can determine the estimated time of deposition, which will have a promising added value to the interpretation phase of the fingerprint evidence in the future. ${ }^{37}$ Furthermore, the development of fingerprints from porous surfaces, such as paper, shows fingerprints deposited from a period exceeding one hundred years. ${ }^{38}$ It is worth mentioning that porous surfaces absorb secretions as well as solid components - the secretions are traces of microelements, so they can penetrate through the porous surface along with the thin fibers of the substrate. Likewise, amino acids, which are among the twenty-two main compon-

35 Ibid.

36 Ibid.

37 S. Pleik et al., "Dating of fingerprints by different mass spectrometric techniques: Analytical and forensic interpretation of latent fingerprint residue", paper presented at the 8th International Symposium on Fingerprints, 4 June 2014, Justus Liebig University Giessen, Lyon.

38 K. Wertheim, op. cit. 
ents of fingerprint secretions, are carried out through pores in paper surfaces and adhere to the molecules of cellulose, which is the main material of the paper, to ensure the stability of these secretions and protect them, which enables them to last for long periods of time. ${ }^{39}$

\section{The information extracted from fingerprint evidence relate only to its physical appearance}

This is a true statement, as almost all fingerprint usage practices have existed for more than 130 years. However, chemical and spectroscopic analyses of fingerprint constituents allow the investigators to gain plenty of information related to the perpetrator.

To emphasize, the external materials that mix with the secretions of the fingerprints are numerous, and they depend mainly on the objects that were held by the perpetrator before touching the bearing surface and depositing the fingermark. It is therefore difficult to limit them to one list or category, such as narcotic substances, pain relievers, tobacco, various types of alcohol, fats and oils from food-such as pizza, hamburgers, French fries, and their metabolites - explosive substances, blood residues, different types of paint and ink, skin moisturizers, cosmetics, oils and materials used in hairdressing, secretions and residues resulting from sexual relations, machinery oils and the fat used in them, etc. It is possible to determine the nature of these materials through laboratory analysis to obtain intelligence information about the lifestyle of the perpetrator as well as their activities and health issues. ${ }^{40}$

Correspondingly, several techniques can be used to extract such information, including Raman spectroscopy - which relies on a spectroscopic analysis of materials by measuring the vibrational molecule patterns - as well as SALDI-TOF-MS and MALDI/TOF MS, which are also spectroscopic techniques that rely on measuring the absorption of laser beams used to analyze the mass spectrometry of biomolecules, polymers,

39 Ibid.

40 W.V. Helmond et al., "Chemical profiling of fingerprints using mass spectrometry", Forensic Chemistry 16, 2019; L.S. Ferguson, Analysis of the composition of latent fingermarks by spectroscopic imaging techniques, doctoral thesis, Sheffield Hallam University, 2013, http://shura.shu.ac.uk/19645/. 
and small organic molecules. These two techniques allow analyzing and measuring mass spectra to show the presence of codeine, cocaine, dimethyl morphine, morphine, papaverine and nonquinine in addition to their metabolites based on the present antigens. The main condition for their use is the prior knowledge of the concerned drugs, narcotics, and medications. ${ }^{41}$

Comprehensive spectroscopy via the laser mass spectrometry aided by laser ionization technology and mass spectroscopy (MALDI MSI) allow the extraction of in-depth information from the molecules of the fingermark constituents. These molecules make it possible to get more knowledge about the suspect, their identity, sex ${ }^{42}$ health, behavior, grooming habits, and lifestyle. They are the narrators of the perpetrators' secrets. Spectroscopy techniques, most notably FTIR and Raman spectroscopy, have helped to determine the presence of narcotic or explosive residue traces on fingerprints in a fingermark. These techniques are rapid, lowcost, and non-destructive to the surface bearing the fingermark. ${ }^{43}$

\section{A lack of visualized fingermarks from the crime scene implies a person did not touch an item}

Fingermarks play an important role in forensic science. Based on the assumption that every individual holds a unique pattern of friction ridge skin on their hands, this pattern can be used for identification. By determining the source of the fingermark, a link between a suspect and a crime scene can be established. ${ }^{44}$ An important question that often comes up in court cases regarding forensic evidence is how or when a trace was deposited.

41 "Forensic breakthrough: Recovering fingerprints on fabrics could turn clothes into silent witnesses", ScienceDaily, 2.02.2011, https://www.sciencedaily.com/releases/ 2011/01/110131073141.htm (accessed: 21.06.2020); L.S. Ferguson, op. cit.

42 C. Heaton et al., "Investigating sex determination through MALDI MS analysis of peptides and proteins in natural fingermarks through comprehensive statistical modelling”, Forensic Chemistry 20, 2020, https://doi.org/10.1016/j.forc.2020.100271.

43 L.S. Ferguson, op. cit.

44 C. Champod et al., Fingerprints and other ridge skin impressions, Boca Raton, FL 2016; R. Cook et al., "A hierarchy of propositions: Deciding which level to address in casework", Science \& Justice 38, 1998, pp. 231-239. 
In the forensic expertise fields of DNA, fibers, glass, paint, and gunshot residues, the evaluation of evidence given activity level propositions is already being studied. ${ }^{45}$ However, for fingermarks this topic is not yet explored. Many variables may provide information on how a fingermark was deposited on a surface. When multiple variables influence the interpretation of the evidence, it can be difficult to take their dependencies into account in a direct likelihood ratio calculation. ${ }^{46} \mathrm{~A}$ method that is commonly used for cases where additional factors play a role is a Bayesian network. It is a graphical representation of a mathematical model that can be used to evaluate findings, particularly if there is a dependency between relevant variables. ${ }^{47}$ A Bayesian network consists of nodes, directed arcs, and probability assignments of the nodes. It can, for instance, be used to compute a likelihood ratio of the evidence given the prosecution proposition and the defense proposition, based on all variables that are considered relevant in the interpretation of the evidence. This makes Bayesian networks an appropriate method to evaluate the evidence given at activity level within the field of forensic science.

\section{A lack of fingermarks implies an item was cleaned or wiped up}

A lack of retrieved fingermarks can be interpreted in many possible ways: the perpetrator did not leave any fingermarks, left an unidentifiable fingermark, the crime scene or laboratory technicians used inappropriate processing techniques, or the fingermark was cleaned or wiped up.

In 2001, Williams and McMurray ${ }^{48}$ first observed that the SKP technique, traditionally used for detecting the onset of corrosion in metals, can be applied in the direct detection of fingermarks on metal surfaces. The process is found to remain effective even after the mark has been wiped from the surface.

45 F. Taroni et al., Bayesian networks for probabilistic inference and decision analysis in forensic science, Chichester 2014.

46 C.G.G. Aitken, A.J. Gammerman, "Probabilistic reasoning in evidential assessment", Journal of the Forensic Science Society 29, 1989, pp. 303-316.

47 F. Taroni et al., op. cit.

48 G. Williams et al., "Time-lapse potentiometric imaging of active filiform corrosion using a scanning Kelvin probe technique", PhysChemComm 4, 2001, no. 16, pp. 26-31, https://doi.org/10.1039/b100835h.

Nowa Kodyfikacja Prawa Karnego 59, 2021

(C) for this edition by CNS 


\section{Automated Fingerprint Identification System (AFIS) makes the identifications}

AFIS does the identification of the ten-print files, as usually the threshold is set high enough, and the fingerprints of many are searched at the same time. However, identifying fingermark traces needs a different procedure. Although AFIS demonstrates a list of candidates to the expert, ACE-V methodology still has to be thoroughly implemented. The fingerprint expert plays a primary role in the process, which requires cooperation between them and the system. The expert needs to follow all the steps of the methodology, analysis, comparison, evaluation, and verification, as well as write the technical report, prepare the chart, interpret the conclusions, testify in court - all this while holding responsibility for the entire process.

The heart of AFIS technology is the ability of a computer to scan and digitally encode the fingerprints. The AFIS uses automated scanning devices that convert the fingerprint image into a digital minutia that contains data showing ridges at their points of termination (ridge endings) and the branching of single ridges into two (bifurcations). The relative position and orientation of the minutiae are also determined, making it possible to store each fingerprint in the form of a digitally recorded geometric pattern.

The computer search algorithm determines the degree of correlation between the locations and mutual relationship of the minutiae for both the search and file prints. In this way, a computer can make thousands of fingerprint comparisons within a second. ${ }^{49}$

\section{Fingerprint conclusions are decisive}

Fingerprint evidence has a high reliability rate. However, the identification process is conducted by human beings who can make mistakes, either by confusion, omission, mis-implementation of the correct procedures, typing errors, etc. Therefore, any genuine concerns about the conclusions have to be taken into consideration, and the conclusion should be rechecked in detail. " $100 \%$ certainty" is a measurement of a person's confidence in the conclusion, not of its accuracy.

49 P. Komarinski, Automatic Fingerprint Identification Systems (AFIS), Burlington, MA 2005. 


\section{It is impossible to retrieve fingerprints from surfaces which were wiped or cleaned}

Even though fingerprint scientists are convinced that it is impossible to process fingermarks from wiped or cleaned substrates, which is partially true in case the object's surface has no reactions with the secretions of the skin, as is the case with glass, porcelain, and hard plastic materials.

Nevertheless, it is a false statement for many other subjects such as copper, stainless steel, iron, and other metal objects. Recently, researchers from Loughborough University in Leicestershire (U.K.) in partnership with the Defense Science and Technology Laboratory (DSTL) carried out an advanced detection technique which allows retrieving fingerprints from problematic exhibits, such as spent ammunition casings, ${ }^{50}$ after being exposed to extremely high temperatures as well as surfaces that have been deliberately washed, wiped out, and cleaned, to get clear visible ridge details of fingermarks. This advancement will make it impossible for criminals to conceal or destroy their fingerprints when attempts have been made to destroy print evidence through burning or washing. These items had previously been extremely challenging or impossible to work with - in addition to fired ammunition cases, this included Improvised Explosive Device (IED) components as well as metal items that had been deliberately cleaned, such as knives and contaminated metallic items. ${ }^{51}$

By the same token, cellulose-based porous substrates such as wood, paper, and cardboard have a high capacity of absorbing fingerprint secretions; semi-porous materials, for instance glossy magazine paper, have a lower ability to absorb fingerprint secretions; non-porous materials, such as glass, have the advantage of being unable to absorb fingerprint components. Porous and semi-porous surfaces consisting of cellulose attract the amino acid components of fingerprint secretions, so these amino

50 "Forensic technology developed at Loughborough University will make it "impossible' for criminals to destroy fingerprint evidence”, Loughborough University, 28.11.2017, http:/www.lboro.ac.uk/news-events/news/2017/november/groundbreakingfingerprint-technology-discovered-/ (accessed: 21.06.2020); Ploughshare Innovations, Case study: Ground-breaking fingerprint technology, 2019. https://www.ploughshareinnovations.com/wp-content/uploads/LFT-Case-Study.pdf (accessed: 21.06.2020).

51 Ibid. 
acids settle inside the texture of the substrate and are protected. ${ }^{52}$ In this case they can persist for decades and scientific research even indicates the possibility of developing impressions of fingerprints on paper documents that are more than 100 years old. ${ }^{53}$ Therefore, wiping these surfaces or cleaning them will have a minimal effect on protected materials that are found inside the substrate long after the cleaning process.

\section{Water constitutes around $98 \%$ of the fingermark components}

Many fingerprint scientists, and not only other fingerprint examiners, are convinced that water constitutes $98 \%$ of fingerprint components, and others admit that water accounts for between 98 and 99,5\% of eccrine sweat secretions. However, the scientific facts are different from these claims ${ }^{54}$. It was evidently shown above how numerous factors that affect the final composition mixture of the fingerprint constituents are. Moreover, a recent study published in Forensic Science International emphasized how erroneous this claim is ${ }^{55}$. By using a method based on published analytical data, theoretical models, and common sense, with emphasizing the interfered exogenous and endogenous sources, it has been determined that sweat is not the mere source of the water content in fingermarks. Moreover, there is no scientific experimental evidence stating that purely eccrine fingermark secretions would contain approximately $98 \%$ of water, due to the evaporation of the water found on the skin, its re-absorption by the skin, as well as deposition mechanisms on the substrate. However, chlorides, amino acids, and other water-

52 A. Girod et al., op. cit.

53 P.D. Barnett, R.A. Berger, "The effects of temperature and humidity on the permanency of latent fingerprints", Journal of the Forensic Science Society 16, 1976, no. 3, pp. 249-254.

54 The Home Office Centre for Applied Science and Technology (CAST), op. cit.; G. de Paoli et al., op. cit.; L.S. Ferguson, op. cit.; A. Girod, R. Ramotowski, C. Weyermann, op. cit.

55 T. Kent, "Water content of latent fingerprints: Dispelling the myth", Forensic Science International 266, 2016, pp. 134-38, https://doi.org/10.1016/j.forsciint.2016.05.016. 
soluble components affect the vapor pressure and consequently evaporation rates, whereas other deposited materials become more concentrated. ${ }^{56}$

Kent estimated the average water content of a natural fingermark would be nearer to $20 \%$ or even lower. Another research based on experimental analysis, hand-washing procedure before the deposition of the eccrine-rich fingermarks (sweat constituents), and the monitoring of mass loss due to substrate heating $\left(40^{\circ} \mathrm{C}\right)$, within the first minutes after deposition observed mass loss ranging from 20 to $70 \% .^{57}$

\section{Conclusion}

Notwithstanding claims to the contrary, the study proves the reliability of fingerprint evidence, raising awareness of the complex mixture of fingermark constituents which supports its persistence over time, as well as the possibility of extracting criminal intelligence by a chemical and/or spectral analysis. At the same time, a lack of fingermarks from an item does not imply that the suspect did not touch it, nor that the item was wiped up. Moreover, it is the fingerprint expert, not the AFIS, who makes the fingerprint identifications, and that is why the fingerprint conclusions are not decisive. Furthermore, numerous technologies are being developed to make fingermarks retrievable from items after being wiped up or cleaned, and after being exposed to sunlight, water flow, rain, or humidity. That depends on the numerous types of molecules found within the fingermark constituents where the water percentage is usually under $98 \%$. The second part of this study will discuss the other fourteen myths about fingerprint evidence.

\section{Conflict of interest}

The authors declare that there is no conflict of interest regarding the paper's publication.

56 Ibid.

57 A. Bécue, H. Eldridge, Ch. Champod, "Interpol review of fingermarks and other body impressions 2016-2019”, Forensic Science International: Synergy 2, 2020, https:// doi.org/10.1016/j.fsisyn.2020.01.013. 


\section{Acknowledgements}

The authors would like to gratefully acknowledge Madame Michele Triplett, the Forensic Operation Manager of King County Regional AFIS Program, for her worthiest support and contribution to this paper by providing new ideas, and for her precious comments, as well as Madame Caroline Gibb from Forensic Biometric Traces unit of the Netherlands Forensic Institute for her precious comments and support.

\section{References}

Aitken C.G.G., Gammerman A.J., "Probabilistic reasoning in evidential assessment", Journal of the Forensic Science Society 29, 1989.

Alberink I., Jongh A. de, Rodriguez C., "Fingermark evidence evaluation based on automated fingerprint identification system matching scores: The effect of different types of conditioning on likelihood ratios", Journal of Forensic Sciences 59, 2014, no. 1, https://doi.org/10.1111/1556-4029.12105.

Archer N.E. et al., "Changes in the lipid composition of latent fingerprint residue with time after deposition on a surface", Forensic Science International 154, 2005, no. 2-3, pp. 224-39, https://doi.org/10.1016/j.forsciint.2004.09.120.

Barnett P.D., Berger R.A., "The effects of temperature and humidity on the permanency of latent fingerprints", Journal of the Forensic Science Society 16, 1976, no. 3.

Bécue A., Eldridge H., Champod Ch., "Interpol review of fingermarks and other body impressions 2016-2019”, Forensic Science International: Synergy 2, 2020, https:// doi.org/10.1016/j.fsisyn.2020.01.013.

Buchanan M.V., Asano K., Bohanon A., Chemical characterization of fingerprints from adults and children, Washington, D.C. 1996.

Champod C. et al., Fingerprints and other ridge skin impressions, Boca Raton, FL 2016.

Cook R. et al., "A hierarchy of propositions: deciding which level to address in casework", Science \& Justice 38, 1998.

Cooper S.L, "Challenges to fingerprint identification evidence: Why the courts need a new approach to finality", Mitchell Hamline Law Review 42, 2016, no. 2, http:// open.mitchellhamline.edu/mhlr/vol42/iss2/8 (accessed: 20.06.2020).

Croxton R.S. et al., "Variation in amino acid and lipid composition of latent fingerprints", Forensic Science International 199, 2010.

Daluz H.M., Fingerprint analysis laboratory workbook, Boca Raton, FL 2018.

De Paoli G. et al., "Photo- and thermal-degradation studies of select eccrine fingerprint constituents", Journal of the Forensic Science Society 55, 2010, no. 4, https://doi. org/10.1111/j.1556-4029.2010. 01420.x.

Dimond S., Harries R., "Face touching in monkeys, apes, and man: Evolutionary origins and cerebral asymmetry", Neuropsychologia 22, 1984. 
Ferguson L.S., Analysis of the composition of latent fingermarks by spectroscopic imaging techniques, doctoral thesis, Sheffield Hallam University, 2013, http://shura. shu.ac.uk/19645/.

Francese S. et al., "Beyond the ridge pattern: multi-informative analysis of latent fingermarks by MALDI mass spectrometry", The Analyst 138, 2013, no. 15, https://www. researchgate.net/publication/236666974.

"Forensic breakthrough: Recovering fingerprints on fabrics could turn clothes into silent witnesses", ScienceDaily, 2.02.2011, https:/www.sciencedaily.com/releases/2011/ 01/110131073141.htm (accessed: 21.06.2020).

"Forensic technology developed at Loughborough University will make it 'impossible' for criminals to destroy fingerprint evidence", Loughborough University, 28.11.2017, http://www.lboro.ac.uk/news-events/news/2017/november/groundbreaking-fingerprint-technology-discovered-/ (accessed: 21.06.2020).

Fulton M., "Latent chemistry: Development of fingerprints", Fulton Forensics, 27.11.2017, https://www.linkedin.com/pulse/latent-chemistry-development-fingerprints-mike-fulton/ (accessed: 29.08.2020).

Girod A. et al, "Composition of fingermark residue: A qualitative and quantitative review", Forensic Science International 223, 2012.

Girod A. et al, "Fingermark initial composition and aging using Fourier transform infrared microscopy ( $\mu$-FTIR)", Forensic Science International 254, 2015, https://doi. org/10.1016/j.forsciint.2015.07.022.

Girod A., Ramotowski R., Weyermann C., "Composition of fingermark residue: A qualitative and quantitative review", Forensic Science International 223, 2012, no. 1-3, https://doi.org/10.1016/j.forsciint.2012.05.018.

Heaton C. et al., "Investigating sex determination through MALDI MS analysis of peptides and proteins in natural fingermarks through comprehensive statistical modelling", Forensic Chemistry 20, 2020, https://doi.org/10.1016/j.forc.2020.100271.

Helmond W.V. et al., "Chemical profiling of fingerprints using mass spectrometry", Forensic Chemistry 16, 2019, https://doi.org/10.1016/j.forc.2019.100183.

Hopkins W.D. et al, "Grip preference, dermatoglyphics, and hand use in captive chimpanzees (Pan troglodytes)", American Journal of Physical Anthropology 128, 2005, no. 1, https://doi.org/10.1002/ajpa.20093.

Kaufman R., "Mutated DNA causes no-fingerprint disease", National Geographic, 10.08.2011, https://www.nationalgeographic.com/news/2011/8/110809-fingerprintsskin-disease-health-science-weird// (accessed: 17.08.2020).

Kent T., "Water content of latent fingerprints: Dispelling the myth", Forensic Science International 266, 2016, https://doi.org/10.1016/j.forsciint.2016.05.016.

Kershaw S., Lichtblau E., "Questions about evidence in U.S. arrest in bombing", The New York Times, 22.05.2004, https://www.nytimes.com/2004/05/22/us/questions-aboutevidence-in-us-arrest-in-bombing.html (accessed: 14.06.2020).

Komarinski P. , Automatic Fingerprint Identification Systems (AFIS), Burlington, MA 2005. Maceo A.V., "Anatomy and physiology of adult friction ridge skin", [in:] National Institute of Justice, The fingerprint sourcebook, https://www.ojp.gov/pdffiles1/ nij/225320.pdf.

Nowa Kodyfikacja Prawa Karnego 59, 2021

(C) for this edition by CNS 
"Merocrine gland", Biology Online, https://www.biologyonline.com/dictionary/merocri ne-gland (accessed: 18.06.2020).

"Morphogenèse et composition des empreintes digitales", Police Scientifique, https:// www.police-scientifique.com/empreintes-digitales/composition (accessed: 14.06.2020).

Murota H. et al., "Sweat in the pathogenesis of atopic dermatitis", Allergology International 67, 2018, no. 4.

OpenLearn, The Open University, https://www.open.edu/openlearn/health-sports-psycho $\log \mathrm{y} /$ health/forensic-science-and-fingerprints/content-section- 0 ?active-tab $=\mathrm{de}$ scription-tab (accessed: 14.06.2020).

Pleik S. et al., "Dating of fingerprints by different mass spectrometric techniques: Analytical and forensic interpretation of latent fingerprint residue", paper presented at the 8th International Symposium on Fingerprints, 4 June 2014, Justus Liebig University Giessen, Lyon.

Ploughshare Innovations, Case study: Ground-breaking fingerprint technology, 2019. https://www.ploughshareinnovations.com/wp-content/uploads/LFT-Case-Study. pdf (accessed: 21.06.2020).

Richter M., Wright R., “Autonomic nervous system”, [in:] Encyclopedia of behavioral medicine, New York 2012, https://www.researchgate.net/publication/280650893 _Autonomic_nervous_system.

Su C., Srihari S., "Evaluation of rarity of fingerprints in forensics", Proceedings of Neural Information Processing Systems, 6-9 December 2010, Vancouver, Canada, https:// cedar.buffalo.edu/ $\sim$ srihari/papers/nips2010.pdf.

Swofford H.J. et al., "A method for the statistical interpretation of friction ridge skin impression evidence: Method development and validation", Forensic Science International 287, 2018, https://doi.org/10.1016/j.forsciint.2018.03.043.

Taroni F. et al., Bayesian networks for probabilistic inference and decision analysis in forensic science, Chichester 2014.

The Home Office Centre for Applied Science and Technology (CAST), Fingermark visualisation manual, 2014, http://www.officialpublicationsonline.co.uk.libproxy.abertay.ac.uk/publications/download/9781782462347.

U.S. Department of Justice, A review of the FBI's handling of the Brandon Mayfield case, March 2006.

Victoria Forensic Science Center Fingerprint Branch, Latent fingerprint composition, FPB training unit module 9, 2011.

Wertheim K., "Fingerprint age determination: Is there any hope?", Journal of Forensic Identification 53, 2003, no. 1.

Williams G. et al., "Time-lapse potentiometric imaging of active filiform corrosion using a scanning Kelvin probe technique", PhysChem Comm 4, 2001, no. 16, pp. 26-31, https://doi.org/10.1039/b100835h.

Yamashita B., French M., "Latent print development", [in:] National Institute of Justice, The fingerprint sourcebook, https://www.ojp.gov/pdffiles1/nij/225320.pdf.

Zhu Y. et al., "Statistical models for assessing the individuality of fingerprints", IEEE Transactions on Information Forensics and Security 2, 2007, no. 3. 